\title{
A Defensive Shield: Strategies to Tackle Global Coronavirus Outbreak in Future
}

\author{
Bosco Jose $^{1}$, Meeti Punetha ${ }^{2}$, Jaya Bharati ${ }^{3}$, Pranay Kumar Konda ${ }^{1}$, Einstien Chris ${ }^{4}$, \\ Manoj Kumar Tripati ${ }^{1}$ and Mihir Sarkar ${ }^{1 *}$
}

${ }^{1}$ Physiology \& Climatology Division, Izatnagar, Bareilly, ICAR-Indian Veterinary Research Institute, Uttar Pradesh-243122, India

${ }^{2}$ ICAR-Central Institute for Research on Buffaloes, Hisar, Haryana-125001, India

${ }^{3}$ Animal Physiology, ICAR-National Research Centre on Pig, Guwahati, Assam, India

${ }^{4}$ Division of Veterinary Virology, Mukteshwar, ICAR-Indian Veterinary Research Institute, Uttarakhand-263138, India

*Corresponding author

\section{A B S T R A C T}

\section{Keywords}

COVID-19,

Vaccine, Antivirals, Artificial

intelligence, Data base, Wildlife trade

Article Info

Accepted:

28 July 2020

Available Online:

10 August 2020
The Coronavirus Disease 2019 (COVID-19) is the largest threat to humankind in recent decades. COVID-19 is a severe acute respiratory syndrome (SARS) caused by SARS-CoV-2 that emerged from the epicenter Wuhan of China in December 2019. It has been spreading like a wildfire across countries and tolled 6,55,112 human lives up to 29 July 2020. The SARS in 2002, Middle East Respiratory Syndrome (MERS) in 2012 and now COVID-19, the chains of deadly coronavirus outbreak have been emerging and the next one will be there in the near future. So that, one health concept centred wholistic approach as a defensive shield to tackle global coronavirus outbreak in the future has been discussed in this review. The defensive shield against future coronavirus outbreak includes comprehensive vaccine tool for animals and humans, low cost and less toxic broad-spectrum antiviral agents (BSAAs) and supplementary therapeutics, artificial intelligence and machine learning-based solutions, generation of a pan-accessible coronavirus database with intergovernmental partnerships, a complete ban on wildlife trade with sensitization of animal owners, and make science and research as a global priority. It is the right time to be humane and to follow belligerent measures to fight against another pandemic.

\section{Introduction}

Nature is the best teacher. Over a while, nature has shown its grace and curse towards the little creatures who try to manipulate the mainland forown bliss. The humanity again is in the cradle of pandemics. We are in a time that can compare to the pre- penicillin (the 
first antibacterial drug) era. The Coronavirus Disease 2019 (COVID-19) outbreak is the largest threat to humanity in recent decades sweeping across borders and sending ripples to nook and corner of the globe. The COVID19 is a severe acute respiratory syndrome (SARS) that emerged from the epicenter Wuhan of China in December 2019 (Zhouet al., 2020). The Severe Acute Respiratory Syndrome -Coronavirus-2 (SARS-CoV-2), is the etiology of the deadly and rapidly transmitting COVID-19 (CSG 2020). As said earlier, the entire humanity bowed and dusted in front of a viral pandemic. The similar chapters of the outbreak in 2002 as SARS (Song et al., 2019) and in 2012 as Middle East Respiratory Syndrome (MERS) (Zumla et al., 2015) warned humankind to take the belligerent measures to save our future generations. The strides of COVID-19 should be an eyeopener for us. The future coronavirus outbreak is inevitable and it may happen in this decade itself. There is no wonder in that. According to an experienced virologist Dr Peter Daszak, there are more than 500 new coronaviruses in bats in China and among six of them had antibodies in local populations. Also, the world's largest emerging zoonotic prediction project, 'The Predict' had exposed over 800 novel viruses across different species. Of course, the bats were the frontrunner with half in their baggage and followed by non-human primates (Gruber, 2017). So, the pandemic threat for the future generation is real, like a rock.

\section{A defensive shield}

At this point, everyone may nod that, there is no single ingredient solution to defend the future inevitable outbreak which may be from a small city of any countries where human disrupts the harmony of nature. But, a shield of the 'wholistic approach' around one health concept can be a central defender against the future pandemic. This shield against extinction underscores the rivet popper hypothesis of Paul Ehrlich, a famous Ecologist who stressed the importance of each species for an ecosystem. Similarly, the components revolving around one health concept have its irreplaceable position in the defensive shield to fight against future coronavirus outbreak as shown in Fig. 1.

\section{Comprehensive vaccine tool as a lynchpin}

Referring to Andre FE 2001, preventive and therapeutic vaccines are the main checkpoint against infectious diseases. To date, there is no vaccine tool approved against SARS CoV, MERS CoV, and SARS-CoV-2 infections by US FDA. The comprehensive vaccine tool (Fig. 2) against coronaviruses of humans and animals is the lynchpin of this approach. Since several viruses are evolving across species, the vaccines targeting this outbreak in humans alone might not control the future event. Instead, vaccine tools targeting coronaviruses both in humans, as well as domestic animals may serve the purpose. Also, the concept of one vaccine to multiple strains of coronaviruses (Fig. 2) needs to get support to avoid the other deadly outbreaks. The whole inactivated virus, viral subunits, virus-like particles (VLPs), the recombinant viruses, and DNA plasmids expressing viral proteins are the main approaches for vaccine development. Among, the most conventional being is the whole-cell killed or liveattenuated vaccines. Since, these vaccines have the risk of introducing infectious viruses (Graham et al., 2012), safer alternatives in the form of subunit vaccines, DNA vaccines, and mRNA vaccines are under development. Subunit vaccines based on Trimer-Tag technology (Liu et al., 2017) and molecular clamp technology (Takashima et al., 2011) are underway and offer great promise (Zhang et al., 2020). DNA vaccines like INO-4800 offer a wide range of immune responses by direct injection of DNA plasmids encoding 
the SARS-CoV-2 spike are currently under trial (Yang et al., 2004; Ahn et al., 2020). The mRNA vaccines have advantages like nonexistence of genomic integration, superior immune responses, quick development protocol for the production of multimeric antigens (Pardi, 2018). Moderna, Inc. has developed mRNA-1273, an mRNA vaccine encoding viral spike (S) protein of SARSCoV-2, and has already started phase I clinical trials for it (Ahn et al., 2020). Also, another potential mRNA vaccine candidate BNT 162 by BioNTech set to enter clinical trials in late April 2020.

Recombinant vaccine incorporating adenovirus type 5 vector (Gonzalez-Nicolini et al., 2006), live modified horsepox virus vaccine (TNX 1800), Hyleukin-7 platform technology, plant derived SARS-CoV-2 Virus-Like Particle (VLP) based constructs, synthetic amino acid hybrid peptides and recombinant intranasal vaccine using protein nanoparticle technology (Philippidis, 2020) are few among many vaccine candidates which are in the preclinical study phase and could prove to be a big shield against SARS$\mathrm{CoV}-2$ in the coming days. From the beginning of April 2020, phase III clinical trials have been initiated among health care workers of Australia and Netherlands using the $\mathrm{BCG}$ vaccine to decrease the incidence and impact of COVID-19. The reduced morbidity and mortality of populations having universal policies of BCG vaccination make it relevant for alternative treatment regimens of COVID-19 and it may help to tackle the future respiratory tract infections (Miller et al., 2020). Recently, ChAdOx1 nCoV-19, a chimpanzee adenovirus-vectored vaccine candidate expressing SARS-CoV-2 spike protein from University of Oxford, UK, safely elicited both humoral and cellular immune response (Folegatti et al., 2020) and it may be the panacea for this pandemic.
Conventional and innovative diagnostic and therapeutic strategies

\section{Antivirals and immunotherapeutic agents}

The discovery of penicillin and other antibiotics were the life-saving golden moments of the $20^{\text {th }}$ century. Like that, as time passes the significance of antiviral pharmaceuticals has risen. A handful of repurposed Broad-spectrum antiviral agents (BSAAs) such as remdesivir (Wang et al., 2020) a viral RNA-dependent RNA polymerase inhibitor, lopinavir (Lin et al., 2020) a viral protease inhibitor, ribavirin (Jones et al., 2004) a ribonucleic analog, arbidol (umifenovir) (Zhang et al., 2020) a membrane fusion inhibitor, favipiravir a viral RNA polymerase inhibitor, and other supplementary pharmaceuticals like chloroquine (Wang et al., 2020) have been made an impact in the COVID-19 outbreak. More recently, the FDA approved antiparasitic drug ivermectin found to effectively inhibit the SARS-CoV-2 in vitro (Caly et al., 2020). The discovery of efficient broad-spectrum antivirals with less toxicity and cost is the need of the hour or repurposing the existing ones will be the cheaper alternative in the short course (Fig. 3). As the situation worsens, the targeted immunotherapy can be a complementary tool to defend the present as well as future coronavirus outbreaks. The pro-inflammatory response of the body should be modulated without compromising the beneficial host defense mechanism. Monoclonal antibodies like CR3022 bind with receptor binding domain (RBD) and neutralise the virus may make it a promising candidate for the COVID-19 outbreak (Li et al., 2020). Alternatively targeting the IL6 and its receptor (Liu et al., 2020) by monoclonal antibodies like tocilizumab (Fu et al., 2020) reduces the COVID-19 induced cytokine release syndrome in severe patients (Liu et 
al., 2020). The fast-evolving nature of coronaviruses may be the main checkpoint for the antibody therapies. A cocktail antibody therapy can be the solution for this and it already proposed to tackle the Ebola pandemic. Since antiviral antibodies are found to be present in the convalescent plasma from recovered patients, so that convalescent plasma therapy is an option for the future coronavirus outbreak (Li et al., 2020). The possibility to use angiotensin converting enzyme (ACE) 2 inhibitors and their limitations to tackle coronavirus are well explained by the Kruse (2020).

\section{Stem cell therapy for COVID-19}

The stem cell therapy opens up another possibility to treat COVID-19 patients. Especially, Mesenchymal Stem Cells (MSCs) due to its immunomodulatory effects in tissues make them the candidate for treatment. Among adipose, amniotic and umbilical cord (UC) MSCs, the UC-MSCs are the preferable choice due to factors like a) one of the richest source of MSCs (Arutyunyan et al., 2016) b) are scalable (fast doubling time) (Weiss et al., 2006), which suits the demand of millions of cells for a large number of COVID-19 patients c) nontumorigenic (Nagamura-Inoue et al., 2014) d) immunoevasive (Tipnis et al., 2010) due to low expression of major histocompatibility complex (MHC) class I molecules and absence of class II molecules of MHC e) safety of MSCs were well documented through several clinical trials (Golchin et al., 2018). There is a cytokine storm phenomenon in COVID-19 patients (Mehta et al., 2020) and the intravenous administration of MSCs can prevent the cytokine storm and repair the lung epithelial tissue with creating a pulmonary microenvironment to recover from virus attack (Leng et al., 2020). The entrapment of a large number of MSCs in the lung makes the recovery effective and faster. Recent case studies from China, UC-MSCs alone or combinations with immunomodulators could be the successful strategies to tackle the coronavirus outbreak (Li et al., 2020) and also, it could treat the acute COVID-19 patients (Leng et al., 2020).

\section{CRISPR; tool for diagnosis and therapeutics}

The innovative Clustered Regularly Interspaced Short Palindromic Repeats (CRISPR) based tools offer ultrasensitive diagnostic prospects for any emerging diseases. The Sherlock (Specific Highsensitivity Enzymatic Reporter unlocking) CRISPR SARS-CoV-2 Kit from Sherlock Biosciences is the first CRISPR based diagnostic test approved by FDA for an infectious disease. The Sherlock is an RNA guided Cas13a based detection tool for RNA or DNA sequences with attomolar sensitivity (Kellner et al., 2019). The DETECTR (DNA Endonuclease Targeted CRISPR Trans Reporter) is the second CRISPR based diagnostic platform for coronaviruses validated by Mammoth Biosciences (Broughton et al., 2020). It is a rapid assay guided by RNA and using Cas13a to cleave DNA viral sequences and reporters collaterally. The CARAVER (Cas13-helped limitation of viral articulation and readout) is one of the CRISPR based antiviral therapeutic platforms (Freije et al., 2019) which may help to tackle future coronavirus outbreak. The Prophylactic Antiviral CRISPR in human cells (PAC-MAN) aids to reduce viral infections through inhibiting their replication inside cells (Abbott et al., 2020). This CRISPR based new approach also can target recent outbreak and coming coronavirus outbreaks. In future, the All-In-One Dual CRISPR-Cas12a (AIOD CRISPR) (Ding et $a l .$, 2020), Combinatorial Arrayed Reactions for Multiplexed Evaluation of Nucleic acids (CARMEN) (Ackerman et al., 2020), 
SHERLOCK Testing in One Pot (STOP) will be the leaders in the molecular diagnostic platforms for deadly outbreaks. In the foreseen future, they may be the front runner in both diagnostic as well as therapeutic interventions because of their precision and simplicity.

\section{AI and machine learning}

Now, the scientific community across the world is more dynamic than the virus itself. In this digital era, artificial intelligence (AI) based drug development may be the next game changer for facing an uncertain future. The AI based drug developers can target the potential viral genomes faster than the conventional research community.

The efficient data collection on COVID-19 and its processing using $\mathrm{AI}$, machine learning and deep learning will facilitate the diagnosis, treatment, prevention (Fig. 4) and better hospital management in this outbreak as well as in similar events in the future (Alimadadi et al., 2020). AI platforms aid in early detection of corona outbreaks, to alert the healthcare sector as early as possible. Also, it helps the diagnosis of corona cases with the support of medical imaging techniques like X-rays (Salman et al., 2020) (Wang et al., 2020), Computed tomography (CT) (Gozes et al., 2020) (Li et al., 2020) and Magnetic resonance imaging (MRI). It could act as the multi-pronged platform for the monitoring and treatment of the positive cases, contact tracing, and projection of the morbidity and mortality in region-wise (Vaishya et al., 2020).The AI based methods can predict the corona outbreak trajectory in a country with reasonable accuracy (Hu et al., 2020). A recent study conceptualised the algorithm for early identification of corona cases which will reduce rapid the spread of the outbreak in the susceptible populations (Rao et al., 2020).

\section{Generation of pan-accessible Corona virus database}

The surveillance of potential coronaviruses out in nature and its pan-accessible database are much needed for quick action in the future (Fig. 5). The successful intergovernmental and public-private partnerships will make it possible. The roll-out of 'The Predict project' in 2009, based at the One health institute, University of California funded by United States Agency for International Development (USAID) was the right step in this direction. This project had almost 2500 members, spreads across 30 countries (Gruber, 2017). Based on the analysis of results, they used to track down or go for an educated guess on the upcoming zoonotic diseases. The concept of developing a self-database of coronaviruses in a country and depositing of those data into a pan accessible database should be a timebound responsibility for particular countries. The developed and developing nation's government should fund this venture for underdeveloped counterparts. As mentioned earlier, the coronavirus outbreak vibrations tremble all over the world. So, without an inclusive effort, there may not be any permanent solution to face an uncertain future.

\section{Complete ban on wildlife trade}

Nothing less than the complete ban of wildlife trade and minimizing habitat destruction is the other rivets of this defensive shield. The SARS CoV like viruses almost identical to SARS CoV was first identified in masked civet cats (Paguma larvata) and a racoon dog in a wild animal market in China (Guan et al., 2003). Some studies suggested that the pangolins (Manis javanica) could harbour SARS-CoV-2 related ancestral beta-CoVs (Lam et al., 2020). Considering the outbreak of SARS $\mathrm{CoV}$ and SARS CoV-2, the involvement of the wildlife market in the 
emergence of these diseases was undeniable (Daszak et al., 2020). The COVID-19 was originated in a seafood market of Wuhan, China,and $70 \%$ of emerging transferrable diseases were originated from wild animals (Chakraborty et al., 2020). This shows the importance of a complete ban on wildlife trade for a safer future. It is not the first encountered zoonotic transmission of an unknown strain of virus to human populations due to an unrestricted human-animal interface (Murdoch et al., 2020). After COVID-19 outbreak, China comprehensively banned the trade and consumption of wildlife products. Still, there are some loopholes like, this ban doesn't cover the non-food wildlife products such as the Pangolins scale which can be used for medicine (Staden, 2020). Without the complete ban on wildlife trade, even a layman can predict that there will be a chain of coronavirus outbreak in the coming decades. The cost of a pandemic like COVID-19 is certainly outweighing the profit margin of wild animal trade in the name of culture and medicine. The next pandemic can be from anywhere, not only from wildlife, it may emerge from any domestic animals, animal product industry, unhygienic handling of animal products at any point in the supply chain (Fig. 6). So that safer domestic animal management practices, higher quality standards for animal products, and hygienic handling of animal products should be part of law and culture. The pet animal industry and pet owners should be sensitized about the risk factor involved in their daily business.

\section{Science and research; global priorities}

Globally, governments spend their lion share of the budget on the defence purpose rather than funding education and research. The COVID-19 crisis is an eyeopener for the governments and other funding agencies. The immediate support for postdoctoral fellows and budding researchers (Gibson et al., 2020), also funding of mainstream research community targeting coronaviruses should be the prime concern for the funding agencies. Moreover, investments in research and development overall will support the future generation in their miserable time. For example, the production of animal models susceptible to potential pathogens will aid the researchers to develop the therapeutic strategies to target the disease as quickly as possible (Li et al., 2020). The inclusive development of science and research along with enhanced scientific transparency (Gibson et al., 2020) must be the core of the post COVID-19 era. The rearrangement of the healthcare sector as a whole and, hospital operations management especially should be the priorities for the coming decades. The health care workers must be well facilitated with personnel protective equipment and salary remunerations for the unexpected tomorrows. Last but not least, the community that lives beside the animal habitats should be empowered to eliminate the expected spillover in the near future. Personnel hygiene should be the core of health education for any community.

In conclusion, each rivet of this defensive shield for future Coronavirus outbreak is irreplaceable, as each species is inevitable for a balanced ecosystem. The comprehensive vaccine tool for different coronavirus strains, conventional and innovative diagnostic and therapeutic strategies, AI and machine learning-based developments, generation of pan-accessible coronavirus database, a complete ban of wildlife trade globally, and making science and research as a global priority are the irreplaceable rivets of our defensive shield. The one health concept which stresses the human, animal, and shared environment should be promoted for a better future. "Prevention is better than cure", this famous quote of Dutch philosopher Desiderius Erasmus is valid till humankind exists. Otherwise, nature as a wise master will teach valuable lessons in his way. 


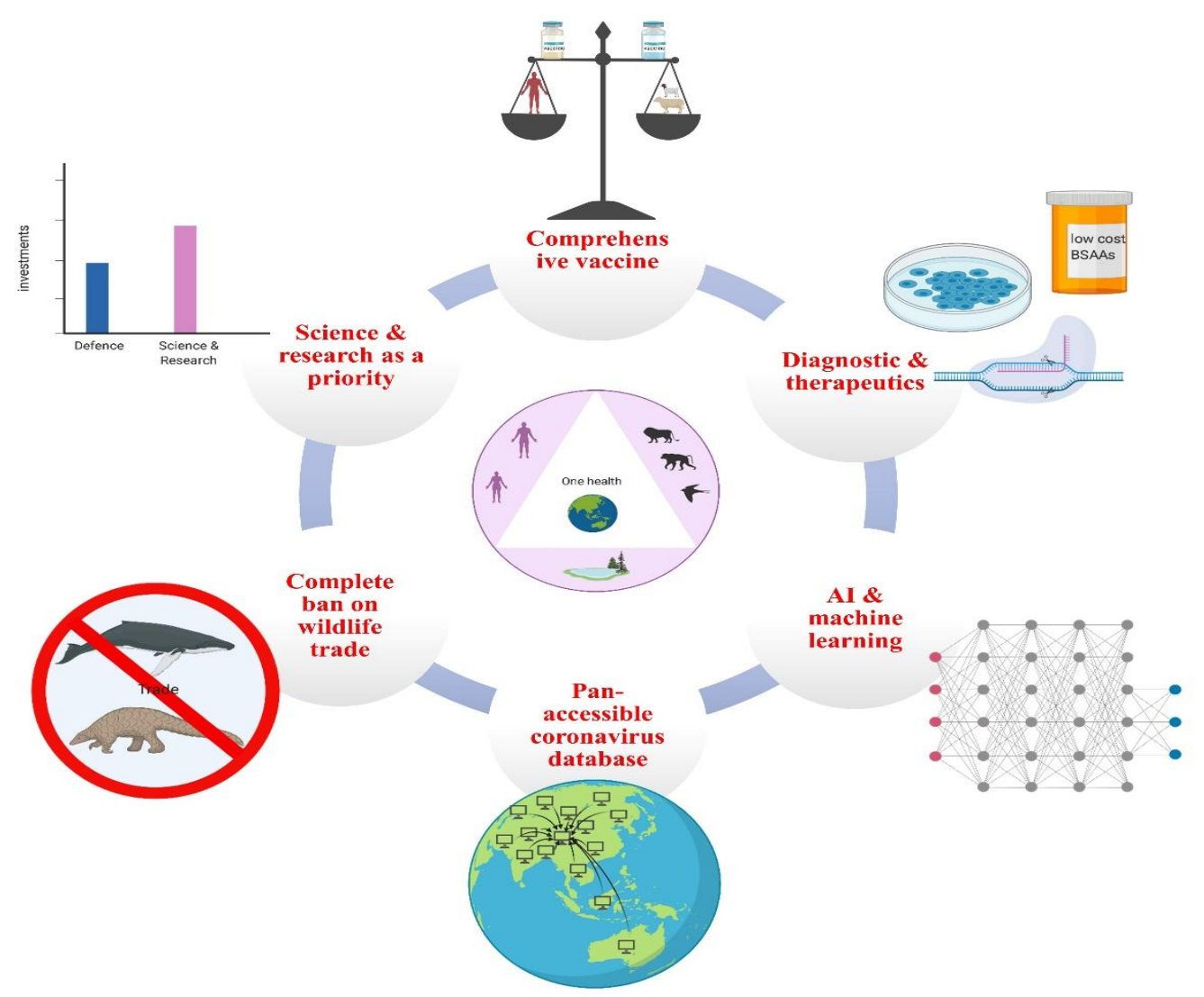

Fig.1 Defensive shield to fight against future coronavirus outbreak.

(Figure created with biorender)
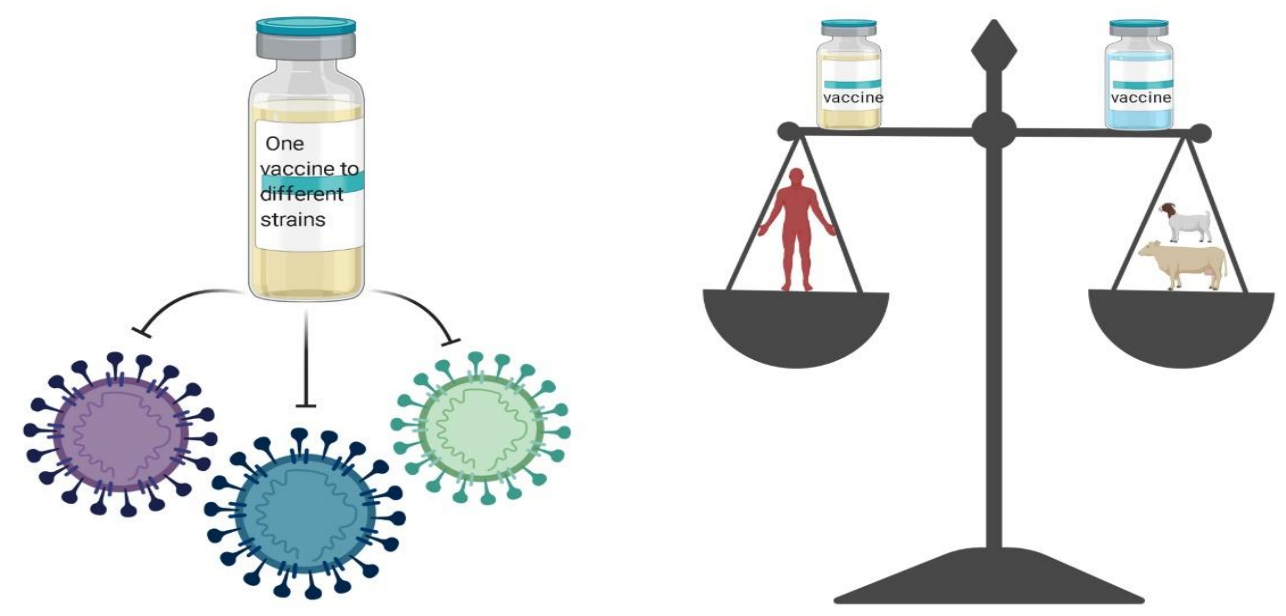

Fig.2 One vaccine to multiple strains of coronaviruses (left side), Importance of comprehensive vaccine tool (right side). (Figure created with biorender) 


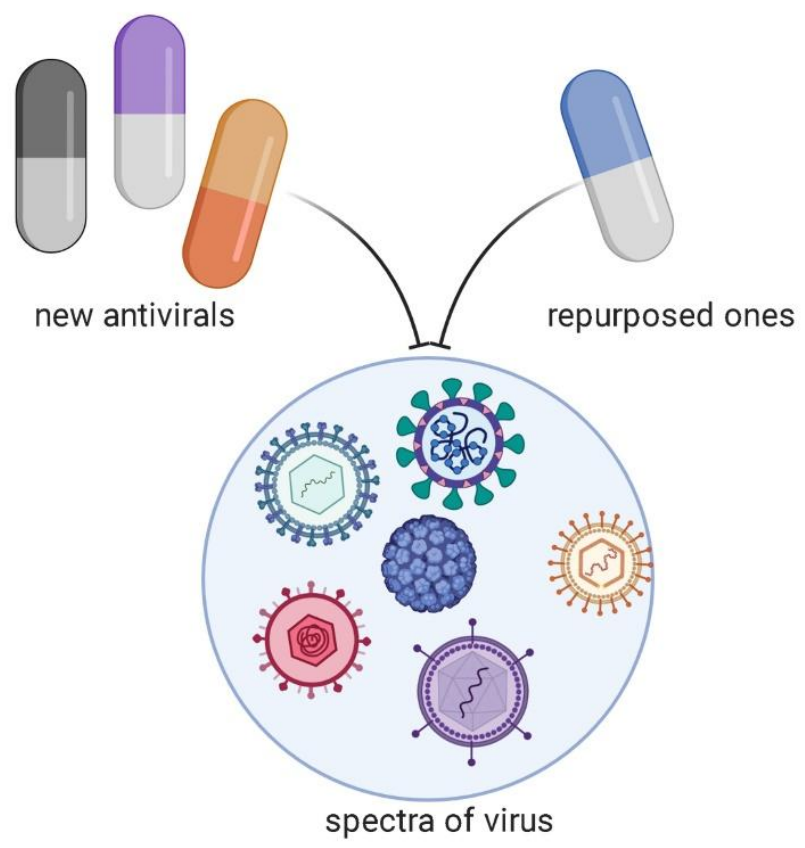

Fig.3 New and repurposed BSAAs. (Figure created with biorender)

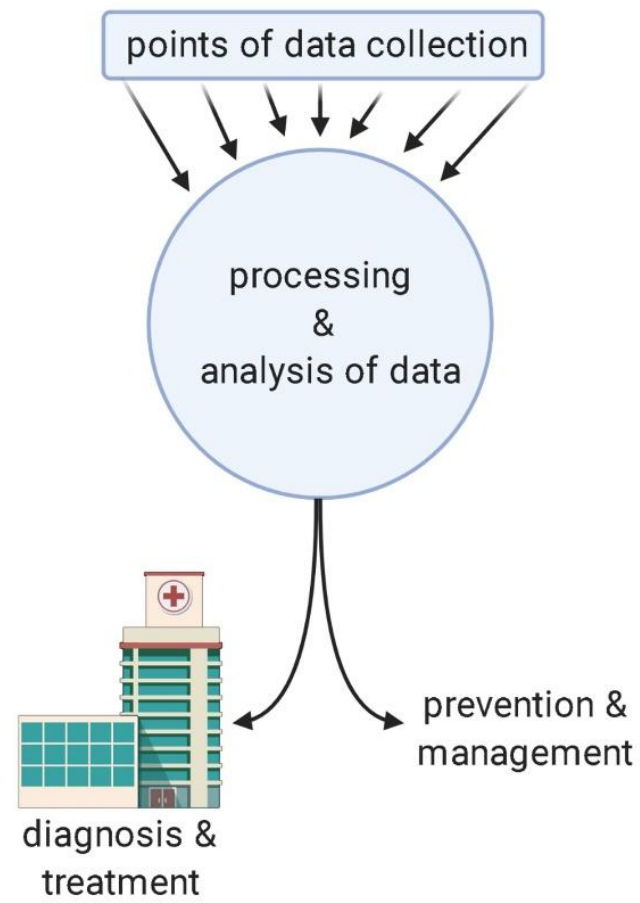

Fig.4 AI and machine learning for quicker response. (Figure created with biorender) 


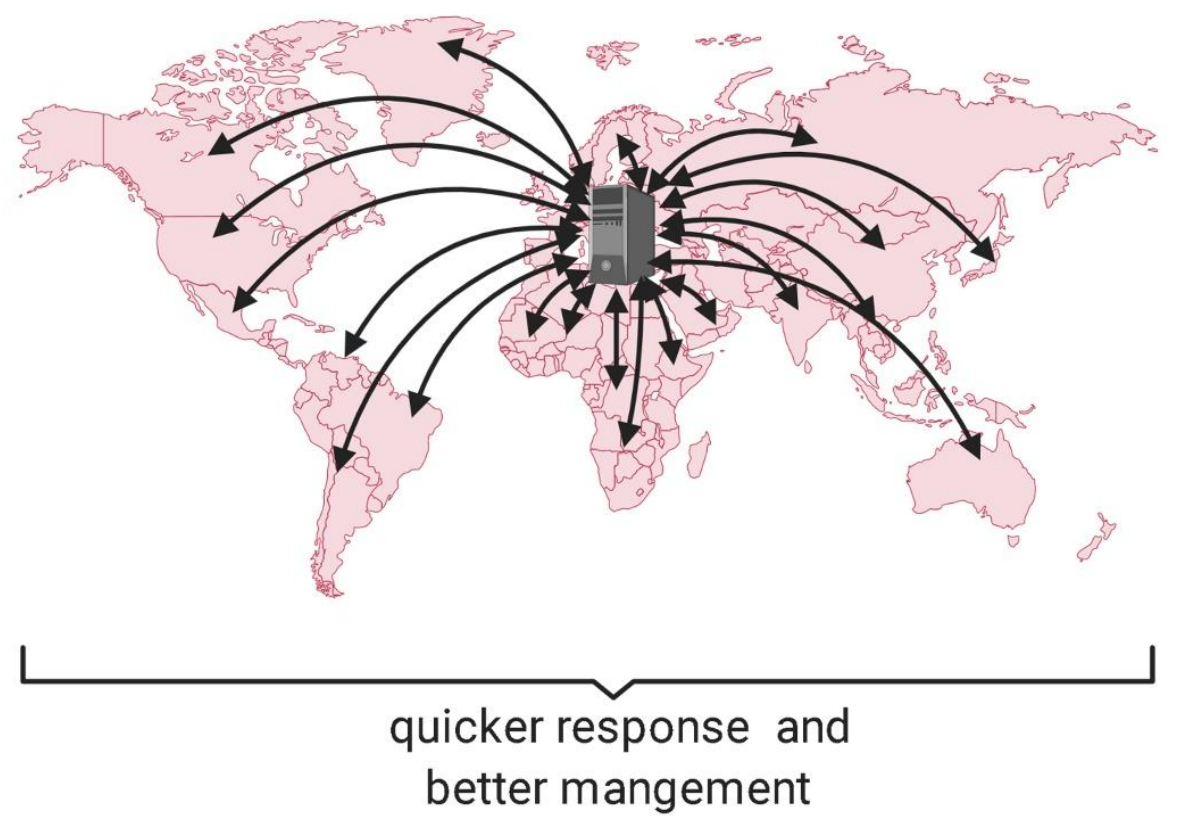

Fig.5 Pan-accessible data base and bidirectional data flow. (Figure created with biorender)

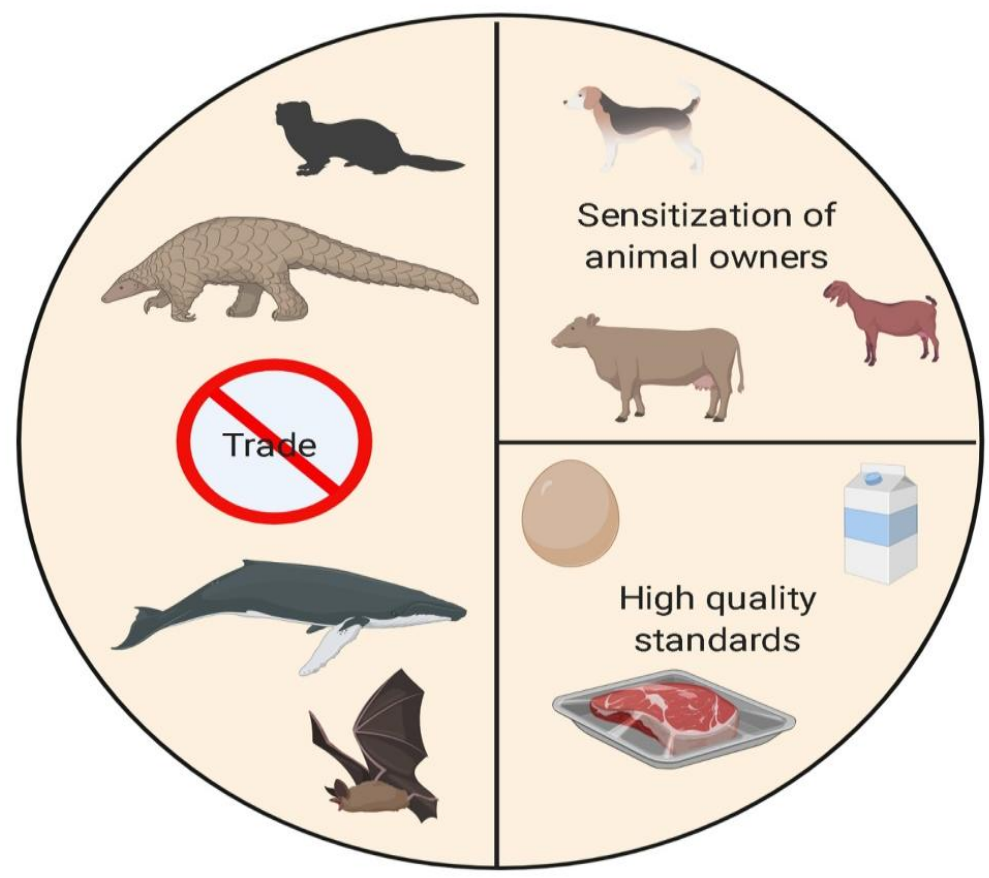

Fig.6 Tangible areas where stringent measures are needed. (Figure created with biorender) 


\section{References}

Abbott, T.R., Dhamdhere, G., Liu, Y., Lin, X., Goudy, L.E., Zeng, L., Chemparathy, A., Chmura, S., Heaton, N., Debs, R., Pande, T., Endy, D., Russa, M. La, Lewis, D.B., Qi, L.S., 2020. Development of CRISPR as a prophylactic strategy to combat novel coronavirus and influenza. Cell 181, 865876.

https://doi.org/https://doi.org/10.1016/j.cell. 2020.04.020

Ackerman, C.M., Myhrvold, C., Thakku, S.G., Freije, C.A., Metsky, H.C., Yang, D.K., Ye, S.H., Boehm, C.K., Kosoko-Thoroddsen, T.S.F., Kehe, J., Nguyen, T.G., Carter, A., Kulesa, A., Barnes, J.R., Dugan, V.G., Hung, D.T., Blainey, P.C., Sabeti, P.C., 2020. Massively multiplexed nucleic acid detection using Cas13. Nature 582, $277-$ 282. https://doi.org/10.1038/s41586-0202279-8

Ahn, D.G., Shin, H.J., Kim, M.H., Lee, S., Kim, H.S., Myoung, J., Kim, B.T., Kim, S.J., 2020. Current status of epidemiology, diagnosis, therapeutics, and vaccines for novel coronavirus disease 2019 (COVID19). J. Microbiol. Biotechnol. https://doi.org/10.4014/jmb.2003.03011

Alimadadi, A., Aryal, S., Manandhar, I., Munroe, P.B., Joe, B., Cheng, X., 2020. Artificial intelligence and machine learning to fight COVID-19. Physiol. Genomics 52, 200202.

https://doi.org/10.1152/physiolgenomics.00 029.2020

André, F.E., 2001. The future of vaccines, immunisation concepts and practice, in: Vaccine. Elsevier, pp. 2206-2209. https://doi.org/10.1016/S0264-

410X(00)00546-6

Arutyunyan, I., Elchaninov, A., Makarov, A., Fatkhudinov, T., 2016. Umbilical Cord as Prospective Source for Mesenchymal Stem Cell-Based Therapy. Stem Cells Int. 2016, $1-17$.

https://doi.org/10.1155/2016/6901286

Broughton, J.P., Deng, X., Yu, G., Fasching, C.L., Singh, J., Streithorst, J., Granados, A., Sotomayor-Gonzalez, A., Zorn, K., Gopez, A., Hsu, E., Gu, W., Miller, S., Pan, C.-Y.,
Guevara, H., Wadford, D., Chen, J., Chiu, C.Y., 2020. Rapid Detection of 2019 Novel Coronavirus SARS-CoV-2 Using a CRISPR-based DETECTR Lateral Flow Assay, medRxiv. Cold Spring Harbor Laboratory Preprints. https://doi.org/10.1101/2020.03.06.2003233 4

Caly, L., Druce, J.D., Catton, M.G., Jans, D.A., Wagstaff, K.M., 2020. The FDA-approved drug ivermectin inhibits the replication of SARS-CoV-2 in vitro. Antiviral Res. 178, 104787.

https://doi.org/10.1016/j.antiviral.2020.104 787

Chakraborty, I., Maity, P., 2020. COVID-19 outbreak: Migration, effects on society, global environment and prevention. Sci. Total Environ. 728, 138882. https://doi.org/10.1016/j.scitotenv.2020.138 882

Daszak, P., Olival, K.J., Li, H., 2020. A strategy to prevent future epidemics similar to the 2019-nCoV outbreak. Biosaf. Heal. 2, 6-8. https://doi.org/10.1016/j.bsheal.2020.01.00 3

Ding, X., Yin, K., Li, Z., Liu, C., 2020. All-inOne Dual CRISPR-Cas12a (AIODCRISPR) Assay: A Case for Rapid, Ultrasensitive and Visual Detection of Novel Coronavirus SARS-CoV-2 and HIV virus. bioRxiv 2020.03.19.998724. https://doi.org/10.1101/2020.03.19.998724

Folegatti, P.M., Ewer, K.J., Aley, P.K., Angus, B., Becker, S., Belij-Rammerstorfer, S., Bellamy, D., Bibi, S., Bittaye, M., Clutterbuck, E.A. and Dold, C., 2020. Safety and immunogenicity of the ChAdOx1 nCoV-19 vaccine against SARSCoV-2: a preliminary report of a phase $1 / 2$, single-blind, randomised controlled trial. The

Lancet.https://doi.org/10.1016/S01406736(20)31604-4

Freije, C.A., Myhrvold, C., Boehm, C.K., Lin, A.E., Welch, N.L., Carter, A., Metsky, H.C., Luo, C.Y., Abudayyeh, O.O., Gootenberg, J.S., Yozwiak, N.L., Zhang, F., Sabeti, P.C., 2019. Programmable Inhibition and Detection of RNA Viruses Using Cas13. Mol. Cell 76, 826-837.e11. 
https://doi.org/10.1016/j.molcel.2019.09.01 3

Fu, B., Xu, X., Wei, H., 2020. Why tocilizumab could be an effective treatment for severe COVID-19? J. Transl. Med. 18, 164. https://doi.org/10.1186/s12967-020-023393

Gibson, E.M., Bennett, F.C., Gillespie, S.M., Güler, A.D., Gutmann, D.H., Halpern, C.H., Kucenas, S.C., Kushida, C.A., Lemieux, M., Liddelow, S., Macauley, S.L., Li, Q., Quinn, M.A., Roberts, L.W., Saligrama, N., Taylor, K.R., Venkatesh, H.S., Yalçın, B., Zuchero, J.B., 2020. How Support of Early Career Researchers Can Reset Science in the Post-COVID19 World. Cell. https://doi.org/10.1016/j.cell.2020.05.045

Golchin, A., Farahany, T.Z., Khojasteh, A., Soleimanifar, F., Ardeshirylajimi, A., 2018. The Clinical Trials of Mesenchymal Stem Cell Therapy in Skin Diseases: An Update and Concise Review. Curr. Stem Cell Res. Ther. 14, 22-33. https://doi.org/10.2174/1574888x13666180 913123424

Gonzalez-Nicolini, V., Sanchez-Bustamante, C.D., Hartenbach, S., Fussenegger, M., 2006. Adenoviral vector platform for transduction of constitutive and regulated tricistronic or triple-transcript transgene expression in mammalian cells and microtissues. J. Gene Med. 8, 1208-1222. https://doi.org/10.1002/jgm.960

Gorbalenya, A.E., Baker, S.C., Baric, R.S., de Groot, R.J., Drosten, C., Gulyaeva, A.A., Haagmans, B.L., Lauber, C., Leontovich, A.M., Neuman, B.W., Penzar, D., Perlman, S., Poon, L.L.M., Samborskiy, D. V., Sidorov, I.A., Sola, I., Ziebuhr, J., 2020. The species Severe acute respiratory syndrome-related coronavirus: classifying 2019-nCoV and naming it SARS-CoV-2. Nat. Microbiol. 5, 536-544. https://doi.org/10.1038/s41564-020-0695-z

Gozes, O., Frid-Adar, M., Greenspan, H., Browning, P.D., Zhang, H., Ji, W., Bernheim, A., Siegel, E., 2020. Rapid AI Development Cycle for the Coronavirus (COVID-19) Pandemic: Initial Results for Automated Detection \& Patient Monitoring using Deep Learning CT Image Analysis. arXivPrepr. https://doi.org/arXiv ID 2003.05037

Graham, R.L., Donaldson, E.F., Baric, R.S., 2013. A decade after SARS: Strategies for controlling emerging coronaviruses. Nat. Rev. Microbiol. 11, 836-848. https://doi.org/10.1038/nrmicro3143

Gruber, K., 2017. Predicting zoonoses. Nat. Ecol. Evol. 1, 1-4. https://doi.org/10.1038/s41559-017-0098

Guan, Y., Zheng, B.J., He, Y.Q., Liu, X.L., Zhuang, Z.X., Cheung, C.L., Luo, S.W., Li, P.H., Zhang, L.J., Guan, Y.J., Butt, K.M., Wong, K.L., Chan, K.W., Lim, W., Shortridge, K.F., Yuen, K.Y., Peiris, J.S.M., Poon, L.L.M., 2003. Isolation and characterization of viruses related to the SARS coronavirus from animals in Southern China. Science. 302, 276-278. https://doi.org/10.1126/science.1087139

Hu, Z., Ge, Q., Li, S., Jin, L., Xiong, M., 2020. Artificial Intelligence Forecasting of Covid19 in China. arXivPrepr. https://doi.org/arXiv:2002.07112

JONES, B.M., MA, E.S.K., PEIRIS, J.S.M., WONG, P.C., HO, J.C.M., LAM, B., LAI, K.N., TSANG, K.W.T., 2004. Prolonged disturbances of in vitro cytokine production in patients with severe acute respiratory syndrome (SARS) treated with ribavirin and steroids. Clin. Exp. Immunol. 135, 467-473. https://doi.org/10.1111/j.13652249.2003.02391.X

Kellner, M.J., Koob, J.G., Gootenberg, J.S., Abudayyeh, O.O., Zhang, F., 2019. SHERLOCK: nucleic acid detection with CRISPR nucleases. Nat. Protoc. 14, 29863012. https://doi.org/10.1038/s41596-0190210-2

Kruse, R.L., 2020. Therapeutic strategies in an outbreak scenario to treat the novel coronavirus originating in Wuhan, China. F1000 Research 9, 72. https://doi.org/10.12688/f1000research.222 11.2

Lam, T.T.Y., Shum, M.H.H., Zhu, H.C., Tong, Y.G., Ni, X.B., Liao, Y.S., Wei, W., Cheung, W.Y.M., Li, W.J., Li, L.F., Leung, G.M., Holmes, E.C., Hu, Y.L., Guan, Y., 2020. Identifying SARS-CoV-2 related 
coronaviruses in Malayan pangolins. Nature 3, 1-4. https://doi.org/10.1038/s41586-0202169-0

Leng, Z., Zhu, R., Hou, W., Feng, Y., Yang, Y., Han, Q., Shan, G., Meng, F., Du, D., Wang, S., Fan, J., Wang, W., Deng, L., Shi, H., Li, H., Hu, Z., Zhang, F., Gao, J., Liu, H., Li, X., Zhao, Y., Yin, K., He, X., Gao, Z., Wang, Y., Yang, B., Jin, R., Stambler, I., Lim, L.W., Su, H., Moskalev, A., Cano, A., Chakrabarti, S., Min, K.J., Ellison-Hughes, G., Caruso, C., Jin, K., Zhao, R.C., 2020. Transplantation of ACE2- Mesenchymal stem cells improves the outcome of patients with covid-19 pneumonia. Aging Dis. 11, 216-228.

https://doi.org/10.14336/AD.2020.0228

Li, H., Liu, S.M., Yu, X.H., Tang, S.L., Tang, C.K., 2020. Coronavirus disease 2019 (COVID-19): current status and future perspectives. Int. J. Antimicrob. Agents 55, 105951.

https://doi.org/10.1016/j.ijantimicag.2020.1 05951

Li, L., Qin, L., Xu, Z., Yin, Y., Wang, X., Kong, B., Bai, J., Lu, Y., Fang, Z., Song, Q., Cao, K., Liu, D., Wang, G., Xu, Q., Fang, X., Zhang, S., Xia, Juan, Xia, Jun, 2020. Artificial Intelligence Distinguishes COVID-19 from Community Acquired Pneumonia on Chest CT. Radiology 200905.

https://doi.org/10.1148/radiol.2020200905

Lin, S., Shen, R., He, J., Li, X., Guo, X., 2020. Molecular modeling evaluation of the binding effect of ritonavir, lopinavir and darunavir to severe acute respiratory syndrome coronavirus 2 proteases. bioRxivPrepr. 2020.01.31.929695. https://doi.org/10.1101/2020.01.31.929695

Liu, B., Li, M., Zhou, Z., Guan, X., Xiang, Y., 2020. Can we use interleukin-6 (IL-6) blockade for coronavirus disease 2019 (COVID-19)-induced cytokine release syndrome (CRS)? J. Autoimmun. https://doi.org/10.1016/j.jaut.2020.102452

Liu, H., Su, D., Zhang, J., Ge, S., Li, Y., Wang, F., Gravel, M., Roulston, A., Song, Q., Xu, W., Liang, J.G., Shore, G., Wang, X., Liang, P., 2017. Improvement of Pharmacokinetic Profile of TRAIL via
Trimer-Tag Enhances its Antitumor Activity in vivo. Sci. Rep. 7, 1-11. https://doi.org/10.1038/s41598-017-095181

Liu, T., Zhang, Jieying, Yang, Y., Zhang, L., Ma, H., Li, Z., Zhang, Jiaoyue, Cheng, J., Zhang, X., Wu, G., Yi, J., 2020. The Potential Role of IL-6 in Monitoring Coronavirus Disease 2019. SSRN Electron. J. https://doi.org/10.2139/ssrn.3548761

Mehta, P., McAuley, D.F., Brown, M., Sanchez, E., Tattersall, R.S., Manson, J.J., 2020. COVID-19: consider cytokine storm syndromes and immunosuppression. Lancet 395 , 1033-1034. https://doi.org/10.1016/S01406736(20)30628-0

Miller, A., Reandelar, M.J., Fasciglione, K., Roumenova, V., Li, Y., Otazu, G.H., 2020. Correlation between universal BCG vaccination policy and reduced morbidity and mortality for COVID-19: an epidemiological study. medRxiv 2020.03.24.20042937. https://doi.org/10.1101/2020.03.24.2004293 7

Murdoch, D.R., French, N.P., 2020. COVID-19: another infectious disease emerging at the animal-human interface. NZMJ 133, 1510.

Nagamura-Inoue, T., 2014. Umbilical cordderived mesenchymal stem cells: Their advantages and potential clinical utility. World J. Stem Cells 6, 195. https://doi.org/10.4252/wjsc.v6.i2.195

Pardi, N., Hogan, M.J., Porter, F.W., Weissman, D., 2018. mRNA vaccines-a new era in vaccinology. Nat. Rev. Drug Discov. 17, 261-279. https://doi.org/10.1038/nrd.2017.243

Philippidis, A., 2020. Catching Up to Coronavirus: Top 60 Treatments in Development [WWW Document]. URL https://www.genengnews.com/virology/cor onavirus/catching-up-to-coronavirus-top60-treatments-in-development/ (accessed 6.21.20).

Rao, A.S.R.S., Vazquez, J.A., 2020. Identification of COVID-19 Can be Quicker through Artificial Intelligence framework using a Mobile Phone-Based Survey in the Populations when Cities/Towns Are under 
Quarantine. Infect. Control Hosp. Epidemiol. $\quad 41, \quad 826-830$. https://doi.org/10.1017/ice.2020.61

Salman, F.M., Abu-Naser, S.S., Alajrami, E., Abu-Nasser, B.S. and Alashqar, B.A., 2020. COVID-19 Detection using Artificial Intelligence [WWW Document]. URL http://dstore.alazhar.edu.ps/xmlui/handle/12 3456789/587 (accessed 6.21.20).

Song, Z., Xu, Y., Bao, L., Zhang, L., Yu, P., Qu, Y., Zhu, H., Zhao, W., Han, Y., Qin, C., 2019. From SARS to MERS, Thrusting Coronaviruses into the Spotlight. Viruses 11, 59. https://doi.org/10.3390/v11010059

Takashima, Y., Osaki, M., Ishimaru, Y., Yamaguchi, H., Harada, A., 2011. Artificial Molecular Clamp: A Novel Device for Synthetic Polymerases. Angew. Chemie Int. Ed. 50, 7524-7528. https://doi.org/10.1002/anie.201102834

Tipnis, S., Viswanathan, C., Majumdar, A.S., 2010. Immunosuppressive properties of human umbilical cord-derived mesenchymal stem cells: Role of B7-H1 and IDO. Immunol. Cell Biol. 88, 795-806. https://doi.org/10.1038/icb.2010.47

Vaishya, R., Javaid, M., Khan, I.H., Haleem, A., 2020. Artificial Intelligence (AI) applications for COVID-19 pandemic. Diabetes Metab. Syndr. Clin. Res. Rev. 14, 337-339.

https://doi.org/10.1016/j.dsx.2020.04.012

van Staden, C., 2020. COVID-19 and the crisis of national development. Nat. Hum. Behav. 4, 443-444. https://doi.org/10.1038/s41562020-0852-7

Wang, L., Wong, A., 2020. COVID-Net: A Tailored Deep Convolutional Neural Network Design for Detection of COVID19 Cases from Chest X-Ray Images. arXivPrepr.

https://doi.org/arXiv:2003.09871
Wang, M., Cao, R., Zhang, L., Yang, X., Liu, J., Xu, M., Shi, Z., Hu, Z., Zhong, W., Xiao, G., 2020. Remdesivir and chloroquine effectively inhibit the recently emerged novel coronavirus (2019-nCoV) in vitro. Cell Res. 30, 269-271. https://doi.org/10.1038/s41422-020-0282-0

Weiss, M.L., Troyer, D.L., 2006. Stem cells in the umbilical cord. Stem Cell Rev. 2, 155-162. https://doi.org/10.1007/s12015-006-0022-y

Yang, Z.Y., Kong, W.P., Huang, Y., Roberts, A., Murphy, B.R., Subbarao, K., Nabel, G.J., 2004. A DNA vaccine induces SARS coronavirus neutralization and protective immunity in mice. Nature 428, 561-564. https://doi.org/10.1038/nature02463

Zhang, J., Zeng, H., Gu, J., Li, H., Zheng, L., Zou, Q., 2020. Progress and Prospects on Vaccine Development against SARS-CoV2. Vaccines 8, 153. https://doi.org/10.3390/vaccines8020153

Zhang, J., Zhou, L., Yang, Y., Peng, W., Wang, W., Chen, X., 2020. Therapeutic and triage strategies for 2019 novel coronavirus disease in fever clinics. Lancet Respir. Med. 8, e11-e12. https://doi.org/10.1016/S22132600(20)30071-0

Zhou, F., Yu, T., Du, R., Fan, G., Liu, Y., Liu, Z., Xiang, J., Wang, Y., Song, B., Gu, X., Guan, L., Wei, Y., Li, H., Wu, X., Xu, J., Tu, S., Zhang, Y., Chen, H., Cao, B., 2020. Clinical course and risk factors for mortality of adult inpatients with COVID19 in Wuhan, China: a retrospective cohort study. Lancet 395, 1054-1062. https://doi.org/10.1016/S01406736(20)30566-3

Zumla, A., Hui, D.S., Perlman, S., 2015. Middle East respiratory syndrome. Lancet 386, 995-1007. https://doi.org/10.1016/S01406736(15) 60454-8.

\section{How to cite this article:}

Bosco Jose, Meeti Punetha, Jaya Bharati, Pranay Kumar Konda, Einstien Chris, Manoj Kumar Tripati and Mihir Sarkar. 2020. A Defensive Shield: Strategies to Tackle Global Coronavirus Outbreak in Future. Int.J.Curr.Microbiol.App.Sci. 9(08): 3768-3780.

doi: https://doi.org/10.20546/ijcmas.2020.908.435 